\title{
OSTEOPENIA AND OSTEOPOROSIS;
}

\author{
Frequency among females
}

\author{
Dr. Zahid Masood', Dr. Sumera Shahzad ${ }^{2}$, Dr. Ali Saqib ${ }^{3}$, Dr. Khizer Ashraf ${ }^{4}$
}

1. MBBS, MCPS, MPH, MPHR (Australia) Associate Professor

Dept of Community Medicine, University Medical \& Dental College, Faisalabad

2. MBBS, MPH (Australia) Assistant Professor Dept of Community Medicine, University Medical \& Dental College, Faisalabad

3. MBBS, FCPS (Medicine) Asstt Professor, Dept of Medicine Madinah Teaching Hospital, University Medical \& Dental College Faisalabad

4. MBBS, MIPH (Australia) SPO, (Nutrition)World Health Organization (WHO) Islamabad, Pakistan

Correspondence Address: Dr. Zahid Masood University Medical \& Dental College Faisalabad zahidmd27@gmail.com Dr. Sumera Shahzad University Medical \& Dental College Faisalabad sumera_1s@hotmail.com

Article received on

16/01/2014

Accepted for Publication:

08/03/2014

Received after proof reading:

27/05/2014

\section{INTRODUCTION}

Increasing health facilities and availability of latest technology has resulted in increased life expectancy of both men and women in many developing countries like Pakistan'. Half of the women over the age of 60 years live in the developing countries. It is estimated that $4 \%$ of the Pakistani population is over 65 years of age ${ }^{2}$. Women living in developing countries and their health care providers are unable to understand

\begin{abstract}
Objective: Osteopenia and osteoporosis are one of the main health concerns of Pakistani females now days. Our objective was to study the frequency of osteopenia and steoporosis among females in the Faisalabad and its suburbs. Material and Methods: Study study conducted by the Department of Community Medicine, University Medical \& Dental College Faisalabad in a private sector university of Faisalabad city and a private clinic in People's colony, Faisalabad. Study included a total of 600 women. Convenient sampling was done. Study was conducted from 1st January 2013 to 30th September 2013 in six different sessions. Age, marital status, education, socio-economic status (SES), occupation, parity and residence were variables of interest. Bone Mineral Density (BMD) was tested using calcaneal quantitative ultrasound machine and right heel of participant. Machine converted the BMD values into TScore. According to the recommendations of World Health Organization (WHO) participant was considered normal, osteopenic and osteoporotic. SPSS version 16 for windows was used to analyze data. Results were considered significant if $p$ - value was $<0.05$. Results: Our results reflected that $72.9 \%$ of study participants were osteopenic while $2.4 \%$ were osteoporotic and $24.7 \%$ were normal. By place of residence no significant difference was observed, $48 \%$ of rural population and $47 \%$ of urban population was osteopenic and insignificant correlation was found $(p=0.438$ ). However, $46.77 \%$ and $10 \%$ of urban participants were normal and osteoporotic respectively. Education in relation to osteopenia and osteoporosis revealed that $42 \%$ of educated females were osteopenic while $31.33 \%$ of illiterate females were osteopenic $\quad(p>0.05) .69 .88 \%$ married females were osteopenic and $43.22 \%$ unmarried females were osteopenic $(p<0.001)$. Conclusions: In our study frequency of osteopenia and osteoporosis was significantly high in all age groups. There is need for large-scale population-based studies using calcaneal quantitative ultrasound or DEXA scan to assess the prevalence of osteopenia and osteoporosis in the community. Further health education with special reference to balanced diet should be imparted to target population.
\end{abstract}

Key words: $\quad$ Bone Mineral Density, Females, Faisalabad, Frequency, Osteopenia

Article Citation: Masood Z, Shahzad S, Saqib A, Ashraf K. Osteopenia and osteoporosis; frequency among females. Professional Med J 2014;21 (3): 477-483. 
popularity of fast food are main reasons of high prevalence of osteopenia in Pakistani females ${ }^{5}$. According to a population based study, millions of Pakistani population is suffering from osteopenia and osteoporosis. In an ultrasound based study on women aged $45-70$ years, overall prevalence of osteopenia and osteoporosis was $34 \%$ and $16 \%$ respectively. A study in KPK then Frontier Province showed prevalence of osteopenia and osteoporosis $42 \%$ and $29 \%$ respectively ${ }^{7}$. Holistically, this issue even reflects similar results, a study in Saudi Arabia on females of mean age of 35 years had lower BMD than US counterparts due to high parity and prolonged lactation ${ }^{8}$. A study in India reported that osteoporotic fractures in Indian occur 10-20 years earlier as compared to the Caucasians in the West ${ }^{9}$.

Osteopenia refers to bone mineral density (BMD) that is lower than normal peak bone mineral density but not low enough to be classified as osteoporosis. Osteopenia increases the risk of osteoporosis and osteoporotic fractures as the person advances to old age. Osteoporosis is a disease of skeletal system which is characterized by low bone density and deterioration of bone architect and bone tissue. This results in bone fragility and increased risk of bone fractures. 10 Osteoporosis is three times more common in women as compared to men ${ }^{11}$. This high burden of disease, its delirious effects on health and lack of awareness among public and primary health care providers motivated us to study the prevalence of osteopenia and osteoporosis in our local population.

Measurement of bone mass during adult life provides information about bone accumulated from prenatal stage until maturity, also amount of bone loss during aging. Around 30 years of age an individual can achieve peak bone mass ${ }^{12}$. 'Heredity' is considered to be the most important determinant of peak bone mass and other determinants include nutrition, physical activity, hormonal status, smoking and general health of an individual ${ }^{13}$. The imperative risk factors for osteoporosis are Asian race and female sex. Low dietary calcium intake, vitamin D deficiency, multiparity and prolonged lactation are mainly accountable for this high risk in Asian women ${ }^{14}$. The main purpose of study was to determine the prevalence of osteopenia and osteoporosis in Pakistani females in 19 to 65years of age group and to compare the BMD in different age groups, by place of residence, socioeconomic status, education, parity and occupation.

\section{METHODOLOGY}

Study was initiated after approval of Ethical Review Committee. This observational cross sectional study was conducted by the Department of Community Medicine at University Medical \& Dental College Faisalabad in a private sector university and a private clinic in People's colony, Faisalabad. Study included a total of 600 women. Convenient sampling was done. Study was conducted from January 2013 to September 2013 in six different sessions.

Procedure was explained to the participants and pre-test informed consent was taken from the participants. Females of age group 19-65 were included in the study while females above and below this age-group were excluded. Pregnant ladies and females with history of chronic use of steroids and rheumatoid arthritis were also excluded from the study. Data was collected by graduate and post-graduate doctors on pre-tested structured questionnaire. Age, marital status, education, socio-economic status (SES), occupation, parity and residence were variables of interest. Subject were divided into three sub age groups i.e. age less than 30 years, then between 30 to 45 years and more than 45 years. Dual Energy Absorptiometry (DEXA) is the Gold Standard for bone mineral density; however, Quantitative Ultrasound (QUS) is reliable and costeffective alternative, which was used in this study and many other similar studies ${ }^{15,16,17}$.

BMD was tested using calcaneal quantitative ultrasound (BMD SONOST 3000) machine(Fig-1). Quantitative Ultrasound of Calcaneus was used to calculate the BMD (Bone Mineral Density) of right heel. Machine converted the BMD values into TScore. According to the recommendations of 


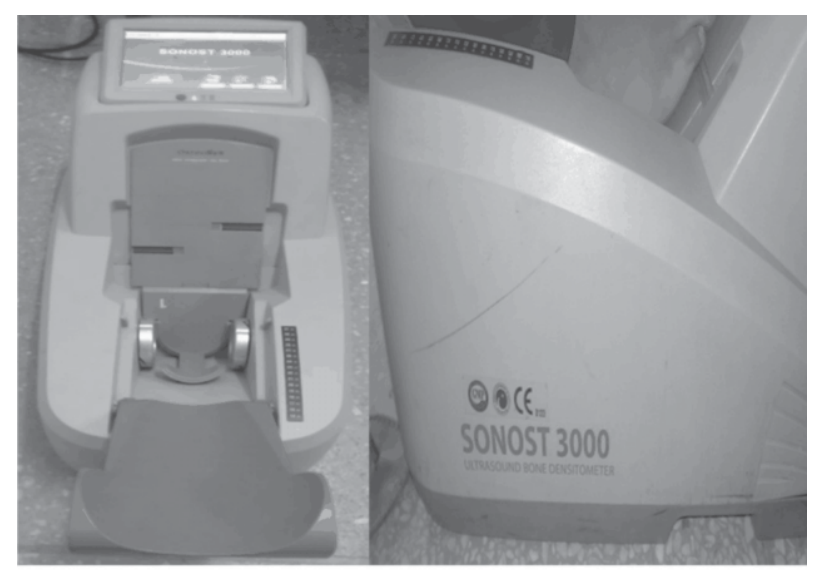

Fig-1. BMD testing apparatus

World Health Organization (WHO), T-Score $<-1$ was considered normal; -1 to -2.5 was considered osteopenia; and T-Score $>-2.5$ was considered osteoporosis ${ }^{18}$ (Fig-2). SPSS version 16 for windows was used to analyze data. Frequencies and percentages were calculated for age-groups, occupation, residence, parity marital status education for osteopenia and osteoporosis. Chi Square test was used to compare various groups. Results were considered significant if $p$ value was $<0.05$.

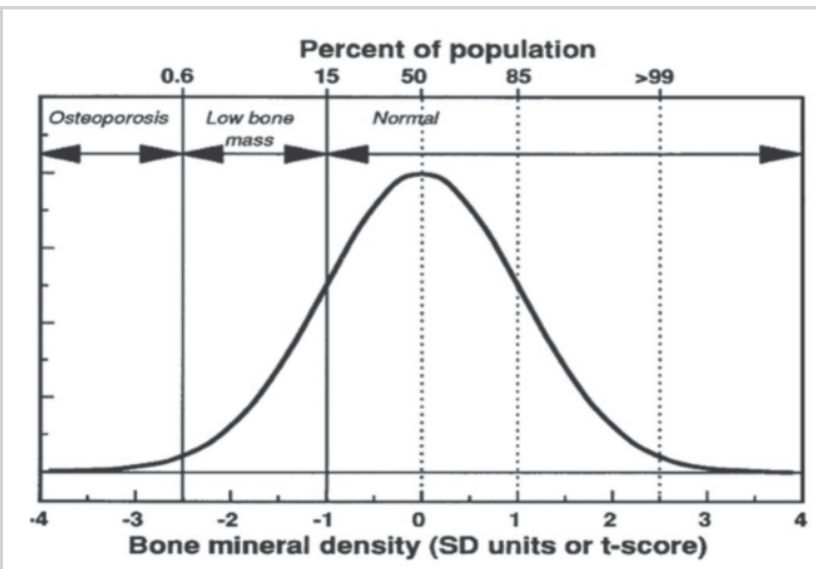

Fig-2. WHO criteria for bone mineral density

\section{RESULTS}

Study included a total of 600 women, 334 were $<30$ years, 189 were between $30-45 y$ ears, and 77 were $>45$ years of age. Our results reflected that $72.9 \%$ of study participants were osteopenic while $24.7 \%$ and $2.4 \%$ were normal and osteoporosis respectively. By place of residence no significant difference was observed, $48.18 \%$ of rural population and $47.14 \%$ of urban population was osteopenic and insignificant correlation was found $(p=0.438)$. However, $46.77 \%$ and $10 \%$ of urban participants were normal and osteoporotic respectively. By occupation we divided our study participants into 3 groups; student, housewife and working women. Our study showed that $50.8 \%$ of students were osteopenic while $56.12 \%$ and $52.5 \%$ of housewife and working women were osteopenic respectively $(p<0.001)$ (Fig-3). Moreover, $41.33 \%$ of females belonging to high class were osteopenic compared to $50 \%$ of middle class. In addition to this, $51.04 \%$ females of lower class were osteopenic $(p<0.001)$. Education in relation to osteopenia and osteoporosis depicted that $42 \%$ of educated females were osteopenic while $31.33 \%$ of illiterate females were osteopenic $(p>0.05) .43 .22 \%$ unmarried females and $69.88 \%$ of married females were osteopenic $(p<0.001)$.

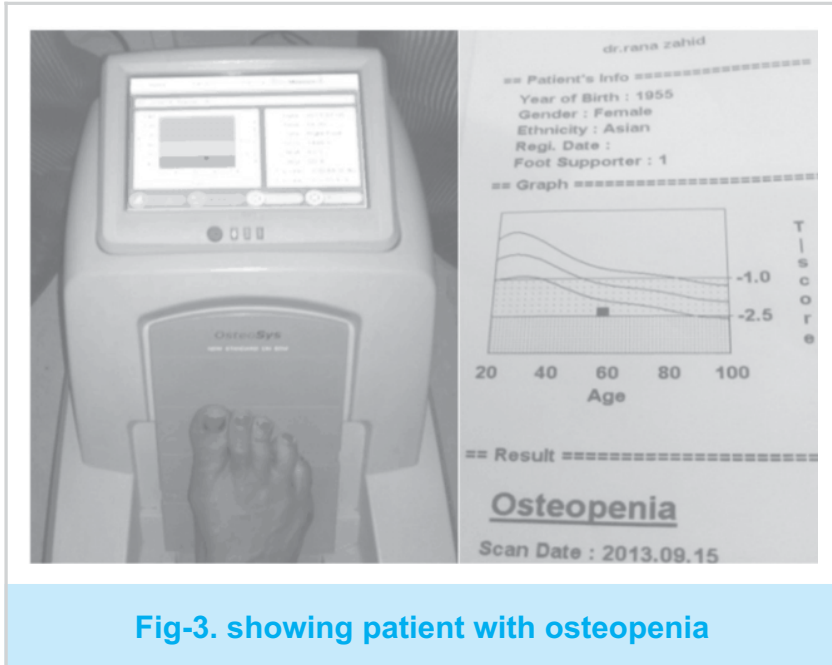

\section{DISCUSSION}

In our study frequency of osteopenia and osteoporosis was high among all age groups. $77.77 \%$ females were osteopenic in age group of $31-45$ years while $38.96 \%$ were osteopenic in age group $>45$ years $(p<0.001)$. A study conducted in Tehran is comparable with our results. It depicts that prevalence of osteopenia was $17.4 \%$ in females of age-group 20-29 years and was $8.3 \%$ in 30-39 years of females. In this study, they also compared mean BMD of their study population 


\begin{tabular}{|c|c|c|c|c|c|}
\hline \multirow[t]{3}{*}{ Characteristics } & \multirow{3}{*}{$\begin{array}{l}\text { Variable affecting bone mineral } \\
\text { density }(n=600)\end{array}$} & \multicolumn{3}{|c|}{ Bone mineral density (BMD) } & \multirow{3}{*}{ p-value } \\
\hline & & Normal & Osteopenia & Osteoporosis & \\
\hline & & $n(\%)$ & $\mathrm{n}(\%)$ & $n(\%)$ & \\
\hline \multirow[t]{3}{*}{ Age } & Woman $<30$ years of age $(n=334)$ & $89(26.64)$ & $238(71.25)$ & $07(2.09)$ & \multirow{3}{*}{$<0.001$} \\
\hline & Woman $31-45$ years of age $(n=189)$ & $38(20.10)$ & $147(77.77)$ & $04(2.11)$ & \\
\hline & Woman $>45$ years of age $(n=77)$ & $27(35.06)$ & $30(38.96)$ & $20(14)$ & \\
\hline \multirow[t]{3}{*}{ Parity } & $(n=55)$ & $48(30.96)$ & $98(63.22)$ & $9(5.80)$ & \multirow{3}{*}{$<0.001$} \\
\hline & $(n=270)$ & $115(42.59)$ & $129(47.77)$ & $26(9.62)$ & \\
\hline & $(n=175)$ & $35(20)$ & $110(62.85)$ & $30(17.14)$ & \\
\hline \multirow[t]{3}{*}{ Occupation } & Working Woman & $15(37.5)$ & $21(52.5)$ & $4(10)$ & \multirow{3}{*}{$<0.001$} \\
\hline & Non-working woman & $101(32.58)$ & $174(56.12)$ & $35(11.29)$ & \\
\hline & Students & $119(47.6)$ & $127(50.8)$ & $4(1.6)$ & \\
\hline \multirow[t]{2}{*}{ Education } & $(n=450)$ & $251(55.77)$ & $189(42)$ & $10(2.22)$ & \multirow{2}{*}{$>0.05$} \\
\hline & $(n=150)$ & $89(59.33)$ & $47(31.33)$ & $14(9.33)$ & \\
\hline \multirow[t]{3}{*}{ SES } & $(n=75)$ & $39(52)$ & $31(41.33)$ & $5(6.66)$ & \multirow{3}{*}{$<0.001$} \\
\hline & $(n=190)$ & $91(47.89)$ & $95(50)$ & $4(2.10)$ & \\
\hline & $(n=335)$ & $135(40.29)$ & $171(51.04)$ & $29(8.65)$ & \\
\hline \multirow[t]{2}{*}{ Marital status } & $(n=445)$ & $99(22.24)$ & $311(69.88)$ & $35(7.86)$ & \multirow{2}{*}{$<0.001$} \\
\hline & Unmarred & $77(49.67)$ & $69(43.22)$ & $9(5.80)$ & \\
\hline \multirow[t]{2}{*}{ Residence } & $(n=490)$ & $210(46.77)$ & $231(47.14)$ & $49(10)$ & \multirow{2}{*}{0.438} \\
\hline & $(n=110)$ & $49(44.54)$ & $53(48.18)$ & $8(7.27)$ & \\
\hline
\end{tabular}

Table-I. Showing variables, their correlation with osteopenia and osteoporosis

PS: It is evident from above table that overall frequency of osteopenia in study participants was 72.9 percent. However, 2.4 percent were osteoporotic and 24.7 percent participants were normal

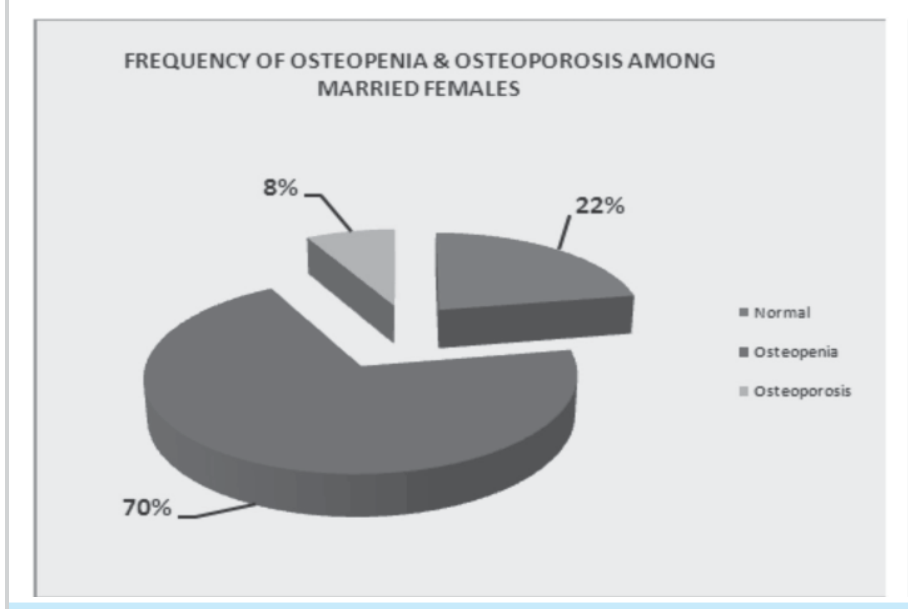

Fig-4 Chart showing frequency of osteopenia \& osteoporosis among married females

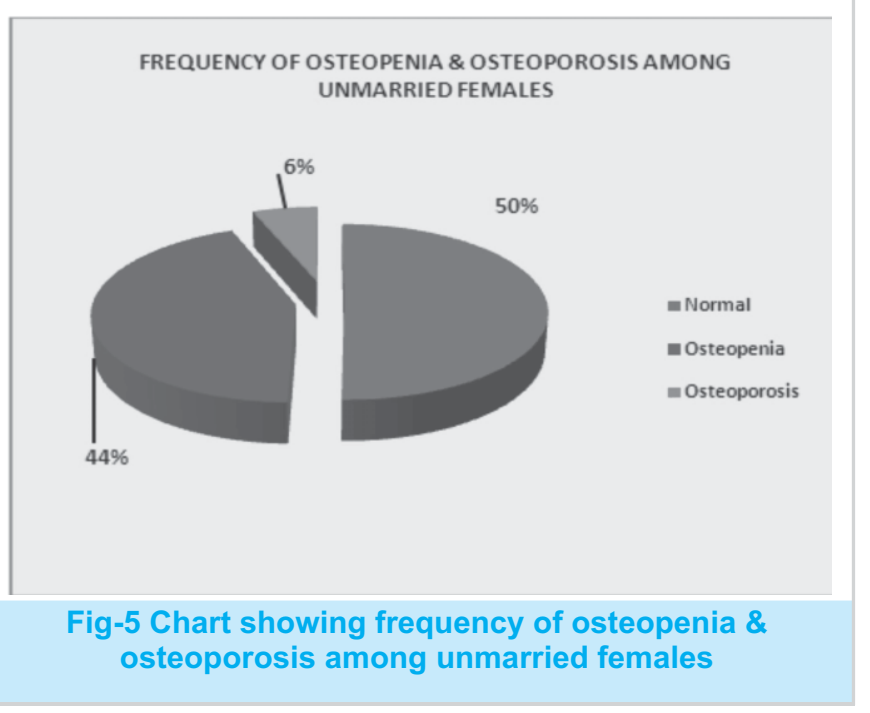

Professional Med J 2014;21(3): 477-483. www.theprofesional.com 
with that their American counterparts, they found that mean BMD of their study population was $5.6 \%$ lower than that of American women ${ }^{19}$. Asian women were 1.56 times greater risk of developing osteoporosis as compared to Caucasian women, as suggested by The National Osteoporosis Risk Assessment Study ${ }^{20}$. Calcium and vitamin D are required for normal bone growth and mineralization. According to the Institute of Medicine, United States, the recommended dietary allowance (RDA) of calcium for females is $1000-1300 \mathrm{mg}$ with increasing requirement in pregnancy and lactation ${ }^{21}$. A high percentage of Pakistani population has deficiency of calcium and vitamin $D^{22}$. A hospital-based study from Karachi reported that $92 \%$ of the out-patients had vitamin D deficiency with female-to-male ratio of $5: 1$. Majority had severe deficiency $(62 \%)^{23}$. The daily calcium intake of an adult Pakistani is between $400 \mathrm{mg}$ and $600 \mathrm{mg}$, in contrast to the recommended daily intake of $1000-1200 \mathrm{mg}^{24}$.

Our study showed that multiparous females specially having more than 4 children were $62.85 \%$ $(p<0.001)$ osteopenic as compared to females having 1-4 children or nulliparous women. This is similar to studies which suggest that multiparity is a risk factor for osteopenia andosteoporosis ${ }^{9,14,25,26}$.

However, two studies showed that high parity was associated with increased BMD. One study was conducted in Lancaster, Pennsylvania on Old Order Amish (OOA) women. These women are known to have less hip fractures as compared to non- Amish Caucasian women. Furthermore, these women have some unique characteristics. They abstain from smoking, alcohol intake and are physically very active ${ }^{27}$. Authors are of opinion that detrainment from these environmental factors which influence BMD, might have confounded results. Second study conducted on Swedish postmenopausal women aged 50-81 years in duration of 2 years. It was population-based casecontrol study. They studied the relationship of parity with risk of hip fracture and they found that parity was modestly associated with reduced hip fracture risk among women who had not used oral contraceptives previously ${ }^{28}$. Another study compared nutrient intake of an adult Pakistani, European and Africo-Caribbean community residing in Manchester City, Britain. The study revealed that Pakistani females were obese and the calcium intake of the Pakistani community was lower than other communities ${ }^{29}$. Decreased calcium intake leads to demineralization and mobilization of calcium from bones which decrease bone mass and results in osteoporosis ${ }^{30}$.

Bone mineral density of urban and rural population reflected that $47.14 \%$ of urban population and $48.18 \%$ of the rural population was osteopenic $(p=0.43)$. However, $10 \%$ of the urban population was osteoporotic in comparison to rural population which was only $7.27 \%$ osteoporotic. Study results clearly point that both urban and rural population are osteopenic and urban population is at increased risk of osteoporosis as compared to rural population due to lack of balanced diet. This is similar to another study conducted in Eastern Poland and found no statistically significant difference in mean values of BMD between urban and rural population. 31 In contrast to that, a study, conducted in Indian population, showed that prevalence of disease was more common in rural population compared with urban population ${ }^{32}$.

We found that working women, students and house wives were osteopenic. $56.12 \%$ of house wives, $52.5 \%$ of working women and $50.8 \%$ of students were osteopenic $(p<0.001)$. This is similar to a study conducted in Poland which showed that BMD values of farmers in rural areas and that of nurses, teachers and retired workers in urban areas, were similar with no statistically significant difference ${ }^{20}$. These findings stress upon the role of genetic predisposition to osteopenia/osteoporosis but also suggest that life-style factors are secondary to them. Jaleel et. al in her study, with no statistically significant difference, found higher frequency of osteopenia and osteoporosis in non-working women as compared to working women and students. Study findings strongly endorsed the importance of physical activity and balanced diet rich in calcium for the prevention of osteopenia and 
osteoporosis $^{5}$. We found that $69.88 \%$ of married females and $43.22 \%$ of unmarried females were osteopenic $(p<0.001)$. The higher frequency of osteopenia and osteoporosis among married females may be attributed to age; poor dietary practices, early marriages, high parity, short birth interval and prolonged lactation ${ }^{8}$.

\section{LIMITATIONS}

Our study has some limitations. Firstly, it was a cross-sectional study which might have over or under estimated the prevalence of osteopenia. Further, we used quantitative ultrasound of calcaneus to calculate BMD. Another limitation of the study was that, sampling frame was limited to only one city and suburbs, because of which the results of this study cannot be generalized for whole Pakistani population.

\section{CONCLUSIONS}

In our study frequency of osteopenia and osteoporosis was significantly high in all age groups. Therefore there is a need for careful consideration in determining risk factors as well as future course of action on scientific grounds. There is need for large-scale population-based studies using DEXA scan or Quantitative Ultrasound (QUS) to assess the prevalence of osteopenia and osteoporosis in the community. Furthermore, people should be educated about the morbidity associated with osteopenia and osteoporosis, the need for increased intake of calcium, especially for females, may be advocated.

\section{Copyright@ 20 Feb, 2014.}

\section{REFERENCES}

1. Cooper C., Campion G., Meltn LJ III., Hip fractures in elderly: a world wide projection. Osteoporos Int (1992), Vol 2 pp 285-289.

2. Samad S, Qureshi R. RH in the national and regional: context. In: Farooqi MS, Samad SA, (edi). Manual for physicians, reproductive health. Karachi: College of Physicians and Surgeons Pakistan; 2002:p.3-8.

3. Baig LA, Karim SA. Age at menopause, and knowledge of and attitudes to menopause, of women in Karachi, Pakistan. J Br Menopause Soc 2006; 12:71-4.
4. Elias C, Sherris J. Reproductive and sexual health of older women in developing countries. BMJ 2003; 327: 64-5.

5. Jaleel F., Nasrullah FD., Khan A., Osteopenia in the young females. Journal of Surgery Pakistan (International) 2010, 15(1).

6. Sultan A, Khan DA, Mushtaq M, Hassan MU. Frequency of osteoporosis and its associated risk factors in postmenopausal women in clinical practice in Rawalpindi. Pak J Pathol. 2006;17:115118.

7. Lowe N, Bano Q, Bangash SA. et al. Dietary cacium intake and bone health in postmenopausal women in Nahaqi, North West Frontier Province, Pakistan. Proceedings of the Nutrition Society. 2008;67.

8. Ghannam NN, Hammami MM, Bakheet SM, Khan BA. Bone mineral density of the spine and femur in healthy Saudi females: relation to vitamin D status, pregnancy and lactation. Calcif Tissue Int. 1999; 65:23-8.

9. Keramat A, Patwardhan B, Larijani B, Chopra A, Mithal A, Chakravarty D. et al. The assessment of osteoporotic risk factors in Iranian women compared with Indian women. BMC Musculoskeletal Disorders 2008; 9:28.

10. Consensus development conference: Diagnosis, prophylaxis and treatment of osteoporosis. American journal of Medicine, 1991, 90:107-110.

11. Assessment of fracture risk and its application to screening for postmenopausal osteoporosis. Report of a WHO Study Group. Geneva, World Health Organization, 1994 (WHO Technical Report series, No. 843).

12. Larijani B., Nezhad AH., Mujtahedi A., Pajouhi M., Bastanhagh $\mathrm{MH}$., Soltani A., et al. Normative data of bone mineral density in healthy population of Tehran, Iran: A cross sectional study. BMC Musculoskeletal Disorders 2005;6:38 Available at URL : www.biomedcentral.com/147-2471/6/38.

13. Bonura F. Prevention, Screening and Management of osteoporosis: An overview of current strategies. Postgrad Med 2009, 121:5-17.

14. Riaz M, Abid N, Patel J, Tariq M, Khan MS, Zuberi L. Knowledge about osteoporosis among healthy women attending a tertiary care hospital. J Pak Med Assoc 2008; 58: 190-4. 
15. Bauer DC, Gluer CC, CauleyJA, Vogt TM, Ensrud $\mathrm{KE}$, Genant HK et al. Broadband ultrasound attenuation predicts fractures strongly and independently of densitometry in older women. A prospective study of osteoporotic fractures research group. Arch Intern Med 1997; 157:629634.

16. Pluijm SM, Graafmans WC, Bouter LM, Lips P. Ultrasound measurements for the prediction of osteoporotic fracture in elderly people. Osteoporosis Int. 1999; 9: 550-556.

17. Khow KT, Reeve J, Luben R, Bingham S, Welch A, Wareham $N$ etal. Prediction of total hip fracture risk in men and women by quantative ultrasound of the calcaneus: EPIC-Norfolk prospective population study. Lancet 2004; 363:197-202.

18. World Health Organization. WHO assessment of fracture risk and its application to screening for postmenopausal osteoporosis: report of a WHO study group. Geneva: World Health Organization, 1994.

19. Larijani B., Nezhad AH., Mujtahedi A., Pajouhi M., Bastanhagh MH., Soltani A., et al. Normative data of bone mineral density in healthy population of Tehran, Iran: A cross sectional study. BMC Musculoskeletal Disorders 2005;6:38 Available at URL : www.biomedcentral.com/147-2471/6/38.

20. Siris ES., Miller PD., Barrett-conner E., Identification and fracture outcomes of undiagnosed loe bone mineral density in post menopausal women results from the National Osteoporosis Risk Assessment. JAMA 2001;286:2815-22.

21. Office of Dietary Supplements, National Institutes of Health. Dietary Supplement Fact Sheet: Calcium. (Online) Updated August 31, 2011. Available from URL: http://ods.od.nih.gov/fact sheets/Calcium-HealthProfessional/.

22. National Nutrition Survey Pakistan, 2011available at URL http://pakresponse.org/pak/sos/uploads/ reports/59_National\%20Nutrition\%20Survey2011.pdf accessed on 3rd September 2013.

23. Zuberi LM, Habib A, Haque N, Jabbar A. Vitamin D deficiency in ambulatory patients. $\mathrm{J}$ Pak Med Assos. 2008; 58: 482-4.

24. Iqbal $\mathrm{R}$, Khan $\mathrm{AH}$. Possible causes of vitamin D deficiency (VDD) in Pakistani population residing in Pakistan. J Pak Med Assos. 2010; 60 pp1-2.

25. Wilkin $\mathrm{CH}$. Osteoporosis screening and risk management. Clinical intervention in aging 2007; 2:389-94.

26. Allali F, Maaroufi H, Aichaoui SE, khazani H, Saoud B, Benyahya B, Abouqal R, Hajjaj-Hassouni N. Influence of parity on bone mineral density and peripheral fractures risk in Moroccan postmenopausal women. Epub 2007; 57(4):392-8.

27. Elizabeth AS, Kathleen AR, Daniel JM, Toni IP, Alan $\mathrm{RS}$, Braxton DM. The relationship between parity and bone mineral density in women characterized by a homogeneous lifestyle and high parity. The Journal of Clinical Endocrinology and Metabolism 2005; 90(8):4536-4541.

28. Michaelsson K, Baron AJ, Farahmand YB, Ljunghall $\mathrm{S}$. Influence of parity and lactation on hip fracture risk. Am. J. Epidemiol. 2001;153(12):1166-1172.

29. Vyas A, Greenhalgh A, Cade J, Sanghera B, Riste L, Sharma $S$, et al. Nutrient intakes of an adult Pakistani, European and African-Caribbean community in inner city Britain. J Hum Nutr Diet 2003; 16: 327-37.

30. Nordin BE. Calcium and osteoporosis. Nutrition 1997; 13: 664-86.

31. Filip RS, Zagorski J. Bone mineral density and osteoporosis in rural and urban women. Epidemiological study of the Lubin region(Eastern Poland). Ann Agric Environ Med 2001;8(2):221-6.

32. Samar, Maletia D, Venkatesan K, Rana S, Anburajan $M$. Screening rural and urban Indian population for osteoporosis using heel ultrasound bone densitometer. Publish in international conference on communication systems and network technologies 2011. Available at URLhttp://ieeexplore.ieee.org/xpl/articleDetails.jsp?reload =true \&arnumber $=5966525$ accessed on 25th July 2013.

\section{CORRECTION}

The amendment of the Professional Vol: 21, No.02 (Prof-2367) on page 316 is as under;

$$
\text { INCORRECT }
$$

Dr. Humayun Suqrat Hasan Imam

Associate Professor of Community Medicine

Punjab Medical College, Faisalabad.

\section{CORRECT}

Dr. Humayun Suqrat Hasan Imam

Assistant Professor of Community Medicine

Punjab Medical College, Faisalabad. 